\title{
Clinical Outcomes of Low Vision Aids for Enhancement of Residual Vision in Diabetic Retinopathy
}

\author{
Mufarriq Shah ${ }^{1}$, Muhammad Tariq Khan ${ }^{2}$ \\ ${ }^{1-2}$ Department of Ophthalmology, Hayatabad Medical complex, Peshawar
}

\begin{abstract}
Purpose: To investigate the clinical outcomes of low vision aids for enhancement of residual vision in patients with Diabetic Retinopathy (DR).

Study Design: Cross-sectional study.

Place and Duration of Study: Hayatabad Medical Complex Peshawar, from January 2018 to December 2019.

Methods: Consecutive patients with DR having poor visual acuity were assessed in a low vision clinic for vision rehabilitation. Data regarding distance and near visual acuity (VA), refractive error, types of low vision aids (LVAs), VA with best correction and with LVAs were collected and analyzed.

Results: Eighty-one patients with mean age of $58.48 \pm 13.54$ years were included in the study out of which $63 \%$ were male. There were $29.6 \%$ Insulin dependent and $70.4 \%$ non-Insulin dependent diabetics with mean duration of 12.6 years of diabetes. At presentation, $63 \%$ had moderate vision impairment (VA $<0.5$ and $>1.0$ ), $14.8 \%$ had severe vision impairment (VA $<1.0$ and $>1.3$ ) and $22.2 \%$ had blindness (VA < 1.3). With LVAs, $97.5 \%$ achieved distance VA of Log MAR 0.4 or better. Mean improvement in distance VA with LVAs was Log MAR $0.95 \pm 0.19$ (P $=0.000 ; 95 \% \mathrm{Cl}$ ). Near VA improved significantly with LVAs and the number of participants who could see $1 \mathrm{M}$ or better with their own glasses increased from $7.4 \%$ to $97.5 \%(p<0.001)$. Binocular telescopes $2.1 \mathrm{X}$ were the most preferred low vision device for distance vision and prismatic magnifying spectacles for near vision.
\end{abstract}

Conclusion: Visual rehabilitation through the use of LVAs was very helpful in patients with low vision caused by diabetic retinopathy.

Key Words: Diabetic retinopathy, blindness, visual rehabilitation, low vision aids.

How to Cite this Article: Shah M, Khan MT. Clinical Outcomes of Low Vision Aids for Enhancement of Residual Vision in Diabetic Retinopathy. Pak J Ophthalmol. 2021, 37 (1): 17-23.

Doi: https://doi.org/10.36351/pjo.v37i1.1138

\section{INTRODUCTION}

Vision impairment and blindness due to diabetic retinopathy (DR) is a major public health problem. ${ }^{1,2}$

Correspondence: Mufarriq Shah

Department of Ophthalmology

Hayatabad Medical Complex, Peshawar

Email: mufarriq1@hotmail.com

Received: August 24, 2020

Accepted: November 11, 2020
There is a significant increase in the number of people with vision loss due to DR over the last two decades. ${ }^{3}$ Globally in 2010, DR accounted for $2.6 \%$ of all blindness and $1.9 \%$ of all moderate and severe vision impairment (MSVI). ${ }^{3}$ In India, the prevalence of vision impairment and blindness due to type 2 diabetes in people of 40 years age and above was reported to be $4 \%$ and $0.5 \%$ respectively. ${ }^{4}$ Vision loss resulting from DR is also likely to increase in low- and middleincome countries with the continued diabetes epidemic. $^{3}$ 
Worldwide prevalence of diabetes is rising and is expected to increase by $20 \%$ in developed countries and $69 \%$ in developing countries by $2030 .^{5}$ The prevalence of DR varies in different countries and is reported to be $19 \%$ in Bangladesh ${ }^{6}, 21 \%$ in China ${ }^{7}$, $28.3 \%$ in Taiwan $^{8}$, and $37 \%$ in Iran. ${ }^{9}$ The prevalence of DR amongst people with diabetes in Pakistan ranges from $17 \%$ to $26 \% .{ }^{10,11}$ People with vision loss due to DR contribute significantly to the number of people with low vision. ${ }^{12,13}$ All people with DR are at risk of vision loss. Despite advancements in eye-care service delivery through innovation in medical and surgical management, it is unlikely to restore vision loss due to DR. It is evident that low-vision rehabilitation of people with vision loss through enhancing residual vision with the use of optical and non-optical low vision aids are successful to improve various aspects of visual performance such as improving distance visual acuity, near visual acuity and reading ability. ${ }^{14,15}$

The purpose of low-vision assessment is to evaluate the individual's functional use of the residual vision. Low-vision rehabilitation aims to help people with impaired vision to learn making the most of a person's residual vision in order to perform activities of daily livings in a better way. ${ }^{14,16}$ According to the World Health Organization, a person with low vision is one who has best corrected distance visual acuity less than $6 / 18$ in the better-seeing eye or a visual field of less than 20 degree in the largest diameter in the better-seeing eye even after treatment. ${ }^{17}$

Majority of people with diabetes seek eye care services only after they have lost their vision due to DR. ${ }^{18}$ Vision loss can lead to loss of productivity and has enormous medical, social, financial and psychological implications. ${ }^{19,20}$ It necessitates the provision of low-vision rehabilitation services to people with vision loss due to DR when medical or surgical treatments are unsuccessful. ${ }^{14,16}$

This study aimed to investigate clinical outcomes of provision of low vision aids for enhancement of residual vision in people with DR in a tertiary eye care center of Pakistan.

\section{METHODS}

This study included 81 patients with diabetic retinopathy (DR), who were assessed for low-vision rehabilitation at a Low Vision Clinic (LVC), Hyatabad Medical Center, Peshawar between January 2018 and
December 2019. This is a tertiary eye care institute in Pakistan. Patients with DR in whom therapeutic interventions could not play a significant role in improving their vision were referred from various hospitals in the province to our LVC for low-vision rehabilitation. Patients with DR included in this study had already been treated medically with intra-vitreal anti-VEGF injections and Laser photo-coagulation. Patients who had some residual vision that could be enhanced with the use of low vision devices were included in the study. Patients with best corrected visual acuity (VA) equal to or better than $6 / 18$ in the better seeing-eye at the time of presentation were excluded from this study. Patients with other pathologies or having multiple causes for vision loss were also excluded from this study. Institutional ethical committee approval was obtained to collect and analyze the hospital-based data and was conducted in accordance with the Declaration of Helsinki.

At the LVC all these participants with DR underwent detailed assessment for visual functions and trial of low vision aids by experienced optometrist. Methods and procedures employed for low vision assessment of these patients included: detailed history of the patient including information about their visual difficulties and previous history of low vision assessment; presenting distance and near visual acuity was recorded in logarithm of the minimum angle of resolution (Log MAR) using a Bailey-Lovie visual acuity assessment chart with five optotypes on each line and final Log MAR distance and near visual acuity with low vision devices.

Distance VA in the better-seeing eye was classified as per WHO classification ${ }^{21}$ : No impairment (distance VA $6 / 18$ or better or Log MAR 0.5 or better); Moderate vision impairment (distance VA 6/18 to 6/60); Severe vision impairment (distance VA $6 / 60$ to $3 / 60$ ) and blindness (distance VA worse than $3 / 60$ ). Near VA was classified in three groups on the basis of reading text size; less than $3.2 \mathrm{M}, 3.2 \mathrm{M}$ to less than $1 \mathrm{M}$, and $1 \mathrm{M}$ (newspaper size) or better and were recorded for each eye separately. ${ }^{13}$ For each patient, the target near visual acuity to achieve with low vision devices was defined on the basis of the text size the patient wanted to read or need of the patient. The text size the patient wanted to read, the distance of eye from the print, equivalent viewing distance (EVD) and equivalent viewing power (EVP) for calculating required magnification and selection of optical devices were noted. 
Single or multiple optical low vision devices were used for assessment of distance and near visual acuities of patients with low vision. This included monocular and binocular telescopes of varying magnification, Ocutech telescope, reading cap with telescope, clip-on filters for patients with photophobia, hand-held and stand magnifiers. Details of the low vision devices used for low vision assessment at the LVC were as follows:

a. MAX TV binocular telescopes (Eschenbach, Germany) are spectacle model telescopes with 2.1 $\mathrm{X}$ magnification. Binocular telescopes are mostly suitable for students for watching black board in the classroom as well as for recognizing faces and watching television in adult population.

b. Monocular telescope ranged from $3 \mathrm{X}$ to $8 \mathrm{X}$ magnification provided from Low Vision Resource Centre Hong Kong Society for the Blind [LVRC-HKSB] used for spotting distant objects.

c. The Ocutech Vision Enhancing System (VES) (Ocutech Inc.) make hands-free magnified vision possible. Various types of Ocutech bioptic telescope have range of magnification from 1.7X (Sight Scope, Galilean telescope design) to 6X (VES-Sport, Keplerian telescope design). Reading caps are also available with Ocutech bioptic telescopes for reading text.

d. Half-eye spectacles up to +10.0 diopters (D) with incorporated base-in prism. These are hand-free magnifiers that allow both the eyes to read together providing greater field of view. These also make the reader more comfortable to write at greater working distance. High-powered single vision reading glasses for better seeing-eye for reading small print size.

e. Hand-held magnifiers ranged from $6 \mathrm{D}$ to $48 \mathrm{D}$ [LVRC-HKSB]. These portable magnifiers are available with and without illumination and are more comfortable for seeing and spotting at a greater working distance. Pocket hand-held magnifiers [LVRC-HKSB] are smaller in size with a wide range of magnification. These are available with and without illumination and mostly used for spotting near tasks.

f. Stand and Dome magnifiers [LVRC, HKSB]. Stand magnifiers are available in a wider range of magnification for seeing very small print size but with limited field of view. Dome magnifiers are available with limited range of magnification.
These have brighter view and are more comfortable for adult population for continuous reading tasks.

g. Closed-circuit television (CCTV). It has a wide range of magnification from $\times 2$ to $\times 25$ and offers the option of contrast change, and freezing of images.

Most participants with severe vision impairment due to DR needed multiple devices (optical and nonoptical) for better improvement in their vision to perform multiple tasks. Trial of single or combination of low vision devices was given to each patient depending on their presenting visual acuity and required task. Detailed explanation and training of use of the low vision device was given to each patient. The maximum improvement in the distance and near visual acuity and types of low vision devices was noted.

SPSS (Statistical Package for Social Sciences) version 19 (IBM Corp, Armonk, NY, USA) was used for analysis of the data. For statistical differences such as between visual acuity prior and with the provision of low vision devices, Paired Samples T-test was conducted. A p-value of less than 0.05 was considered as level of significance. Data was presented descriptively as mean values and standard deviation.

\section{RESULTS}

Out of 81 participants assessed for low vision rehabilitation, 63\% $(\mathrm{n}=51)$ were male. Mean age of the participants was $58.48 \pm 13.54$ years (range: 27 to 80 years). Amongst participants, $29.6 \%(n=24)$ had Insulin dependent diabetes while $70.4 \%(n=57)$ had non-Insulin dependent diabetes. Mean duration of diabetes was $12.6 \pm 6.72$ years. Regarding literacy, $29.6 \%(\mathrm{n}=24)$ were educated and could read and write. Illiterate counted $11.1 \%(\mathrm{n}=9)$ while $59.3 \%$ $(\mathrm{n}=48)$ could read only but could not write. Participants who could read only but could not write asked for low vision aids (LVAs) to help them read the Holy Books and use them in other routine near tasks. All these participants were not satisfied from their own spectacles and wanted improvement in their distance and near vision. None of these participants had received low vision rehabilitation services earlier.

The refractive errors of participants were taken as spherical equivalent. Amongst participants, 48.1\% $(\mathrm{n}=39)$ had hypermetropia (+0.50D or more), $40.7 \%$ $(\mathrm{n}=33)$ had myopia $(-0.50 \mathrm{D}$ or less) and $11.1 \%$ 
Table 1: Age wise distribution of participants based on levels of vision impairment.

\begin{tabular}{llccccc}
\hline Levels of Vision & Distance Visual & & \multicolumn{2}{c}{ Age Groups in Years } & \multicolumn{2}{c}{ Total } \\
Impairment & Acuity (Log MAR) & Less Than 30 & $\mathbf{3 0}$ to 39 & $\mathbf{4 0}$ to 49 & $\mathbf{5 0}$ to 59 & $\mathbf{6 0}$ and Older \\
\hline MVI & VA $<0.5 \& \geq 1.0$ & 3 & 0 & 9 & 15 & 24 \\
SVI & VA $<1.0 \& \geq 1.3$ & 0 & 0 & 3 & 3 & 6 \\
Blind & VA $<1.3$ & 0 & 0 & 3 & 3 & 12 \\
Total & & $\mathbf{3}$ & $\mathbf{3}$ & $\mathbf{1 5}$ & $\mathbf{1 8}$ & 12 \\
\hline
\end{tabular}

Legends: MVI = Moderate vision impairment; SVI = Severe vision impairment

$(\mathrm{n}=9)$ had no refractive error. Mean spherical equivalent refractive error was $-0.25 \pm 3.72 \mathrm{D}$ in right eyes and $0.10 \pm 3.55 \mathrm{D}$ in left eyes. The larger value of SD showed the larger spread of refractive error data ranging from $-11.0 \mathrm{D}$ to $+9.0 \mathrm{D}$ in right eyes and $-9.50 \mathrm{D}$ to $+9.75 \mathrm{D}$ in left eyes. The difference in the means of spherical equivalent refractive error in right and left eyes of these participants was $-0.352 \mathrm{D}(-0.739,0.359$; $95 \% \mathrm{CI})$.

At the time of presentation, $63 \%$ had moderate vision impairment (distance VA less than Log MAR 0.5 to 1.0$), 14.8 \%$ had severe vision impairment (distance VA less than Log MAR 1.0 to 1.3) and 22.2\% had blindness (distance VA less than Log MAR 1.3). About half of the participants were age 60 years and above of whom more than one-fourth were in the blind category. Age wise distribution of participants based on level of vision impairment at the time of presentation is given in Table 1.

Mean Log MAR distance visual acuity prior to the introduction of low vision Aids (LVAs) was $1.10 \pm$ 0.21 . With the provision of LVAs the mean distance VA improved significantly ( $\log$ MAR $0.15 \pm 0.14$; $\mathrm{P}<0.00)$. Mean improvement in distance VA with LVAs was Log MAR $0.95 \pm 0.19(\mathrm{P}=0.000 ; 95 \% \mathrm{CI})$. With the provision of LVAs, 96.3\% $(\mathrm{n}=78)$ of participants could improve to distance VA Log MAR 0.4 or better.

At the time of presentation, 20\% ( $\mathrm{n}=6)$ amongst female participants and $23.5 \%(\mathrm{n}=12)$ amongst male participants were in the blind category. With the provision of LVAs, none of the participants remained in the blind or severe vision impairment categories. Gender wise distribution of participants on the basis of levels of vision impairment at the time presentation and improvement with LVAs are detailed in Table 2.

The overall improvement in near visual acuity with LVAs was statistically significant $(\mathrm{p}<0.001)$. With the provision of LVAs for enhancement of near VA, there was an increase in the number of participants who could discern $1 \mathrm{M}$ text size. Prior to provision of LVAs for near, 7.4\% $(n=6)$ of participants could discern $1 \mathrm{M}$ text size with their own glasses for near. With the provision LVAs, $97.5 \%(\mathrm{n}=$ 79) of participants achieved near VA $1 \mathrm{M}$ or better while $2.5 \%(\mathrm{n}=2)$ had near VA less than $1 \mathrm{M}$.

Table 2: Gender wise distribution of participants based on levels of vision impairment.

\begin{tabular}{|c|c|c|c|c|c|}
\hline \multirow{2}{*}{$\begin{array}{l}\text { Levels of } \\
\text { Vision } \\
\text { Impairment }\end{array}$} & \multirow{2}{*}{$\begin{array}{l}\text { Distance } \\
\text { Visual Acuity } \\
\text { (Log MAR) }\end{array}$} & \multicolumn{2}{|c|}{$\begin{array}{c}\text { At } \\
\text { Presentation }\end{array}$} & \multicolumn{2}{|c|}{ With LVAs } \\
\hline & & $\begin{array}{c}\text { Male } \\
\text { N }\end{array}$ & $\begin{array}{c}\text { Female } \\
n\end{array}$ & $\underset{\mathbf{n}}{\text { Male }}$ & $\underset{n}{\text { Female }}$ \\
\hline Normal & 0.5 or better & 0 & 0 & 48 & 30 \\
\hline MVI & $\mathrm{VA}<0.5 \& \geq 1.0$ & 33 & 18 & 3 & 0 \\
\hline SVI & $\mathrm{VA}<1.0 \& \geq 1.3$ & 6 & 6 & 0 & 0 \\
\hline Blind & $\mathrm{VA}<1.3$ & 12 & 6 & 0 & 0 \\
\hline Total & & 51 & 30 & 51 & 30 \\
\hline
\end{tabular}

Legends: $\mathrm{MVI}=$ Moderate vision impairment

SVI $=$ Severe vision impairment

All of the 51 participants who were in the moderate vision impairment group at presentation were able to discern $1 \mathrm{M}$ or better with LVAs. Amongst 18 participants in the blind group (VA $<$ Log MAR 1.3), two could not discern $1 \mathrm{M}$ with LVAs. Thus participants who had moderate vision impairment at the time presentation achieved better improvement in near vision with LVAs.

Conventional glasses were prescribed to $88.8 \%$ $(\mathrm{n}=72)$ of participants. For distance vision, 2.1X Max TV binocular telescope was the most commonly $(\mathrm{n}=17)$ prescribed low vision device. Amongst the participants $38.3 \%(n=31)$ did not want any telescope for distance. Table 3 show low vision aids prescribed to patients for distance vision.

Prismatic magnifying spectacles (up to +10.0D with base in prism incorporated) were the most accepted low vision device for near vision and were prescribed to 21 participants followed by high plus monocular spectacle lenses $(\mathrm{n}=19)$. Eleven participants did not want any device for near vision 
Table 3: Low vision aids prescribed for distance vision.

\begin{tabular}{lc}
\hline Types of low vision aids & Number \\
\hline 2.1 X Max TV binocular & 17 \\
3X Binocular Telescope & 10 \\
4X Hand Held Telescope & 9 \\
6X Hand Held Telescope & 6 \\
Filters & 7 \\
Ocutech Telescope & 1 \\
Nil (Did not want any telescope) & 31 \\
\hline
\end{tabular}

saying that they did not need. For enhancement in near vision, some participants needed more than one device to perform different tasks. The details of LVDs prescribed for near vision are given in Table 4.

Table 4: Low vision aids prescribed for near vision.

\begin{tabular}{lc}
\hline Types of Low Vision Aids & Number \\
\hline Prismatic magnifying spectacles & 21 \\
High plus monocular spectacle lenses & 19 \\
Illuminated hand-held magnifiers & 16 \\
Pocket magnifiers & 11 \\
Bar magnifier & 6 \\
Dome magnifier & 4 \\
CCTV system & 1 \\
Nil LVAs for near vision & 11 \\
\hline
\end{tabular}

\section{DISCUSSION}

Findings from this study show that majority (63\%) of people with diabetic retinopathy (DR) had moderate vision impairment at the time of presentation. There was a significant improvement in both distance and near visual acuities of participants with the provision of LVAs. Optical low vision devices were the major type of low vision aids dispensed and accepted by people with DR. Participants with moderate vision impairment achieved normal near visual acuity with LVAs. The most preferred low vision devices were 2.1X Max TV binoculars for distance vision and prismatic magnifying spectacles for near vision. All these participants visited for seeking low vision services for the first time.

Similar to the results of this study, the predominance of moderate vision impairment in people with DR has also been reported in other studies. ${ }^{12,14}$ Due to progressive nature of DR, this predominance of moderate vision impairment amongst these people with DR may not sustain. Vision may deteriorate with the passage of time and number of people with moderate vision impairment may decline with an increase in number of people with severe vision impairment and blindness. ${ }^{3,22}$ However, early visual rehabilitation is important to reduce the degree of handicap and strengthen their visual abilities enabling them to manage with vision loss and continue their activities of daily living. ${ }^{23}$

The findings from the present study proved the effectiveness of optical devices for enhancement of distance and near vision in people with DR. Similar to the results of this study, other researcher reported successful use of LVAs as an effective way to help people manage their vision related problems. ${ }^{13,14}$ Despite strong evidence for the effectiveness of low vision devices, it is also evident from this study that $38.3 \%(\mathrm{n}=31)$ of participants with DR deny accepting LVAs. Many factors contributed to their denial such as illiteracy, finances and stigma associated with the usage of low vision aids.

In the light of global epidemic of diabetes and expected increase in number of people with vision loss due to DR, the role of low vision rehabilitation services is pivotal for maintaining independence in activities of daily livings. ${ }^{5}$ Findings from the present study show that none of these participants visited low vision services before. Similar results had been reported in literature indicating most of people with DR were not using low vision services. ${ }^{24}$ These facts indicate that awareness of patients with DR and of their health care providers about the availability of such services is of utmost importance and a key predictor of the use of these services as reported in literature. $^{25}$

Various types of LVAs are available to help people with low vision to cope better with their everyday activities. However, acceptance of type of LVDs is based on individual's preference and needs. Results from this study showed that prismatic magnifying spectacles were the most preferred $(\mathrm{n}=$ 21) LVA followed by high plus monocular spectacle lenses $(\mathrm{n}=19)$, Illuminated hand-held magnifiers (16) and pocket magnifier $(\mathrm{n}=11)$ for performing near task. The preference of these LVAs indicated that older people mostly prefer simpler and cheaper rather than complex and expensive LVAs. Similar results have been reported in other studies. ${ }^{12,14}$ Amongst the participants in our study, only one person was benefited with CCTV while other studies reported greater number of CCTV to participants with vision loss. ${ }^{14}$ In this study, non-affordability was the major obstacle in accepting CCTV for reading purpose. 
An important aspect of this study was that more than half of the participants $(59.3 \%$; $\mathrm{n}=48)$ in our study wanted to read the Holy Books. The needs and expectations of these participants could be different than those of the literate people. Therefore, findings from our study could be different from other studies.

A limitation of this study was that we aimed to quantify the improvement in distance and near visual acuity with the provision of suitable low vision aids in people with DR but could not assess the impact of these LVAs on quality of life of these people. Another limitation is that we did not investigate levels of patient's satisfaction about the vision rehabilitation services. In addition, we could not investigate the factors hindering the acceptance of use of prescribed aids. Further research is needed to explore these factors.

\section{CONCLUSION}

Visual rehabilitation through the use of LVAs proved to be successful in people with diabetic retinopathy. Prismatic magnifying spectacles were the most preferred LVA for near tasks. Awareness about LVAs in people with DR and their eye and health care practitioners is crucial for utilization of low vision services.

\section{Ethical Approval}

The study was approved by the Institutional review board/ Ethical review board. (170/HC/PICO/2020)

\section{Conflict of Interest}

Authors declared no conflict of interest

\section{REFERENCES}

1. Blindness, causes, Priority. Available at: https://www.who.int/blindness/causes/priority/en/index 5.htm. Accessed 5 May 2020.

2. Jonas JB, Nangia $\mathbf{V}$, Khare A. Prevalence and associated factors of diabetic retinopathy in rural central India. Diabetes Care, 2013; 36 (5): e69-e.

3. Pandova MG. Diabetic Retinopathy and Blindness: An Epidemiological Overview, 2019. Available at:

Doi: $\quad$ http://dx.doi.org/10.5772/intechopen.88756. Accessed October 29, 2020.
4. Rani PK, Raman R, Gella L, Kulothungan V, Sharma T. Prevalence of visual impairment and associated risk factors in subjects with type II diabetes mellitus: sankara nethralaya diabetic retinopathy epidemiology and molecular genetics study (SNDREAMS, report 16). Middle East Afr J Ophthalmol. 2012; 19 (1): 129.

5. NCD Risk Factor Collaboration (NCD-RisC). Worldwide trends in diabetes since 1980: a pooled analysis of 751 population-based studies with $4 * 4$ million participants. Lancet 2016; published online April 7. http://dx.doi.org/10.1016/S0140-6736(16)00618-8

6. Ahmed KR, Karim MN, Bhowmik B, Habib SH, Bakht MS, Ali L, et al. Incidence of Diabetic Retinopathy: a 15 Year Follow Up in a Hospital Population (Bangladesh): Diabetes, 2012; 4 (4): 386391.

7. Liu DP, Molyneaux L, Chua E. Retinopathy in a Chinese population with type 2 diabetes: factors affecting the presence of this complication at diagnosis of diabetes. Diabetes Res Clin Pract. 2002; 56 (2): 125 131.

8. Chang C, Lu F, Yang YC. Epidemiologic study of type 2 diabetes in Taiwan. Diabetes Res Clin Pract 2000; 50 Suppl. 2: S49-59.

9. Javadi MA, Katibeh M, Rafati N, Dehghan MH, Zayeri F, Yaseri M, et al. Prevalence of diabetic retinopathy in Tehran province: a population-based study. BMC Ophthalmol. 2009; 9 (1): 12.

10. Jamal-u-Din, Qureshi MB, Khan AJ, Khan MD, Ahmad K. Prevalence of diabetic retinopathy among individuals screened positive for diabetes in five community-based eye camps in northern Karachi, Pakistan. J Ayub Med Coll Abbottabad, 2006; 18 (3): 40-43.

11. Khan AJ. Prevalence of diabetic retinopathy in Pakistani subjects. A pilot study. J Pak Med Assoc. 1991; 41 (3): 49-50.

12. Kalaimathi G, Giridhar A, Saikumar S, Rajesh B, Sreeshma T. Pattern of visual disability and type of low vision aid rehabilitation in a tertiary eye care referral center: A descriptive study. Kerala J Ophthalmol. 2017; 29 (1): 22.

13. Shah M, Khan MD. Causes of low vision amongst the low-vision patients attending the Low-Vision Clinic at Khyber Institute of Ophthalmic Medical Sciences (KIOMS), Hayatabad Medical Complex Peshawar, Pakistan. J Vis Impair Res. 2004; 6 (2-3): 89-97.

14. Gopalakrishnan S, Muralidharan A, Susheel SC, Raman R. Improvement in distance and near visual acuities using low vision devices in diabetic retinopathy. Indian J Ophthalmol. 2017; 65 (10): 995. 
15. Dunbar HMP, Crossland MD, Bunce C, Egan C \& Rubin GS. The effect of low vision rehabilitation in diabetic eye disease: a randomised controlled trial protocol. Ophthalmic Physiol Opt. 2012; 32: 282-293. Doi: $10.1111 / \mathrm{j} .1475-$

16. Hooper P, Jutai JW, Strong G, Russell-Minda E. Age-related macular degeneration and low-vision rehabilitation: a systematic review. Can J Ophthalmol. 2008; 43 (2): 180-187.

17. World Health Organization. The management of low vision in children. Report of a WHO consultation: Bangkok, July 1992. Geneva: World Health Organization, 1993: WHO/PBL/93.27.

18. Murthy GV, Gilbert CE, Shukla R, Vashist P, Shamanna BR. Situational analysis of services for diabetes and diabetic retinopathy and evaluation of programs for the detection and treatment of diabetic retinopathy in India: Methods for the India 11-city 9state study. Indian J Endocrinol Metab. 2016; 20 (Suppl. 1): S19-25. Doi: 10.4103/2230-8210.179770.

19. SJ Leat. A proposed model for integrated low-vision rehabilitation services in Canada. Optom Vis Sci. 2016; 93: $77-84$.

20. Joshi MR, Yamagata Y, Akura J, Shakya S. The efficacy of low vision devices for students in specialized schools for students who are blind in Kathmandu Valley, Nepal. J Vis Impair Blind. 2008; 102 (7): 430-435.
21. Keeffe JE, Taylor HR, Fotis K. Prevalence and causes of vision loss in Southeast Asia and Oceania: 19902010. Br J Ophthalmol. 2014: bjophthalmol-2013304050.

22. Hinds A, Sinclair A, Park J, Suttie A, Paterson H, Macdonald M. Impact of an interdisciplinary low vision service on the quality of life of low vision patients. Br J Ophthalmol. 2003; 87 (11): 1391-1396.

23. O'Connor PM, Mu LC, Keeffe JE. Access and utilization of a new low-vision rehabilitation service. Clin Experiment Ophthalmol. 2008; 36 (6): 547-552.

24. Adam R, Pickering D. Where Are All the Clients? Barriers to Referral for Low Vision Rehabilitation. J Visual Impair Res. 2007; 9 (2-3): 45-50.

\section{Authors' Designation and Contribution}

Mufarriq Shah; Assistant Professor: Concepts, Design, Literature search, Data acquisition, Data analysis, Statistical analysis, Manuscript preparation, Manuscript editing, Manuscript review.

Muhammad Tariq Khan; Associate Professor: Concepts, Design, Literature search, Data acquisition, Manuscript preparation, Manuscript editing, Manuscript review. 